\title{
A quimera do desenvolvimento sustentável para supressão da pobreza e da crise ecológica
}

\author{
The chimera of sustainable development for suppression of poverty and the \\ ecological crisis
}

Raquel Mota Mascarenhas*

\begin{abstract}
Resumo: Esse artigo, sob o suporte teóricometodológico marxista, analisa as particularidades contemporâneas do modo de produção capitalista e as possibilidades de sua superação. Para isso, reflete acerca da relação entre "pobreza e crise ecológica", considerando o paradigma da Agenda 2030 da Organização das Nações Unidas (ONU), e apresenta elementos assertivos da hipótese de que países norteados por projetos societários divergentes Brasil e Cuba, capitalista e socialista, respectivamente - apresentam distintas programáticas de gestão socioambiental em território latino-americano. Assim, utilizando o método comparado e a pesquisa bibliográfica e documental, o trabalho apresenta considerações em três momentos: a relação entre crise ecológica e pobreza na contemporaneidade; o processo de construção da Agenda 2030 da ONU; desenvolvimento sustentável na América Latina, similitudes e particularidades em Brasil e Cuba.
\end{abstract}

Palavras-chaves: capitalismo contemporâneo; crise ecológica; pobreza.

\begin{abstract}
This article, under the support Marxist theory, aims to analyze contemporary particularities of capitalist production mode and possibilities overcoming. For this, reflects on relationship between "poverty and ecological crisis", considering the paradigm Agenda 2030 United Nations (UN), and presents assertive elements hypothesis that countries guided by divergent societal projects - Brazil and Cuba, capitalist and socialist, respectively - present different socio-environmental management programs in Latin American territory. Thus, using comparative method and bibliographical and documentary research, the work presents considerations three moments: the relation between ecological crisis and poverty in contemporaneity; the process building UN Agenda 2030; sustainable development in Latin America, similarities and particularities in Brazil and Cuba.
\end{abstract}

Keywords: contemporary capitalism; ecological crisis; poverty.

* Docente do curso de Serviço Social da Universidade Federal de Ouro Preto; doutoranda em Serviço Social na Universidade Federal do Rio de Janeiro; Mestre em Política Social pela Universidade Federal do Espírito Santo; Graduada em Serviço Social pela Universidade Federal do Espírito Santo. 


\section{Introdução}

Ao observar a relação entre "pobreza e crise ecológica", viso analisar o processo de enfrentamento da pobreza em Brasil e Cuba nos marcos da crise ecológica atual, considerando a Agenda 2030 da Organização das Nações Unidas (ONU). Para tal, utilizo o aporte teórico e metodológico marxista (MARX, 1977); as técnicas de pesquisa bibliográfica (GIL, 2002) e o método comparado (ZEMELMAN, 2003).

Essa contribuição possui relevância social e científica, pois a Agenda 2030, inscrita no documento Transformando Nosso Mundo: A Agenda 2030 para o Desenvolvimento Sustentável apresenta a ação global hegemônica constituída por "governos, parlamentos, o Sistema das Nações Unidas e outras instituições internacionais, autoridades locais, povos indígenas, sociedade civil, os negócios e o setor privado, a comunidade científica e acadêmica" (ONU, 2017: 16). Além disso, por ter sido pactuada em 2015, a Agenda 2030 consiste em um marco recente que carece de maior estudos, com os quais pretendo contribuir ao observar as similitudes e distinções da gestão pública adotada nos países latino-americanos. Entendo, portanto, que países norteados por projetos societários divergentes - Brasil e Cuba, capitalista e socialista, respectivamente - apresentam diferenças de gestão socioambiental, que se expressam, por exemplo, no entendimento da pobreza, da questão ambiental e da política social. Assim, além dessa introdução o trabalho apresenta três momentos: a relação entre crise ecológica e pobreza na contemporaneidade; o processo de construção da Agenda 2030 da ONU; desenvolvimento sustentável na América Latina, similitudes e particularidades em Brasil e Cuba.

\section{Pobreza e crise ecológica na contemporaneidade}

O capitalismo visa produzir valor em detrimento da emancipação humana, através da lei geral de acumulação capitalista (MARX, 1989), que fundamenta a reprodução e acumulação de capital. Desde a fundação, na etapa clássica, passando aos "anos de ouro" e a fase imperialista, o capitalismo é entrecortado por crises, mas essa atinge uma dimensão estrutural a partir da década de 1970, caracterizada por um quadro de barbárie social e ambiental inédita. Acerca dessas implicações, entendo que a crise ecológica atual consiste na particularidade contemporânea da "questão ambiental"1, cuja gênese está na ruptura do metabolismo entre humanidade e natureza, que consiste no "[...] retorno dos componentes da

\footnotetext{
${ }^{1}$ Usa-se a aspas para demonstra que a questão ambiental não se trata de um fenômeno natural e sim historicamente construído (MOTA; SILVA, 2009).
} 
terra consumidos pelo homem, sob forma de alimentos e vestuários, à terra, portanto, a eterna condição natural de fertilidade permanente do solo" (MARX, 1996: 132). Essa ruptura é imersa a relações de produção capitalistas que imperam via a propriedade privada dos meios de produção, sendo o desenvolvimento das forças produtivas tangenciado pelo fim de obter lucro. Assim, a reprodução de capital inviabiliza a manutenção da vida na bioesfera e "[...] destrói simultaneamente a saúde física dos trabalhadores urbanos e a vida espiritual dos trabalhadores rurais" (MARX, 1996: 132). Logo, o capital é um limite à vida, que se expressa no plano político - à exemplo da permuta da poluição industrial para os países periférico - e no plano econômico, transformando degradações em mercadorias, principalmente, via capitalização da natureza (CHESNAIS; SERFATI, 2003).

Embora a gênese da questão ambiental esteja pari passu à emergência do capitalismo, no tempo contemporâneo sua manifestação está particularizada via “[...] o aumento da poluição do ar e da água, a destruição da camada de ozônio, o acúmulo de lixo, o esgotamento dos recursos naturais não renováveis, o avanço da desertificação etc.” (SILVA, 2010: 162). Igualmente, seu enfrentamento a partir final do século $\mathrm{XX}$, é provocado por diversas organizações da sociedade e se constitui via estratégia hegemônica do desenvolvimento sustentável, cujos “principais sujeito da construção [...] são os organismos internacionais" (SILVA, 2010: 177).

Essa estratégia, iniciada na década de 1970 e consolidada na década de 1990, se materializa de duas formas, diretamente articuladas: o discurso ideo-político e a programática teórico-metodológica (SILVA, 2010). A primeira compreende um discurso que se pretende consensual, requerendo para si o status de única alternativa possível para reestabelecer o equilíbrio no metabolismo entre humanidade e natureza, em contraponto ao socialismo real e ao estado de bem-estar social. Para tal, tem-se um receituário do agir individual sustentável, "[...] criando-se no plano ideológico o fetiche da humanização do capital, a partir das mudanças atitudinais" (SILVA, 2010: 238). A segunda refere-se a programática de organismos multilaterais, liderados pela ONU, cujo norteamento teórico-metodológico, a todo tempo, envolveu a pobreza como causa da degradação ambiental, a partir de "[...] duas concepções distintas: a tese do "círculo vicioso", que se fez hegemônica até início dos anos 1990 e a do "duplo caminho", que ganha centralidade no debate ambiental daí em diante" (SILVA, 2010: $34)$.

A tese do círculo vicioso, de origem neomalthusiana, expressa pelo Clube de Roma no relatório Limits to growth, de 1972, expõe que a degradação ambiental advém de um desequilíbrio entre população e quantidade de recursos naturais, responsabilizando os países 
pobres e sua grande população. Consideram que "os pobres são sujeitos e vítimas do processo de dilapidação da natureza", pois demandam mais recursos ao mesmo tempo em que vivenciam áreas de maior degradação. Assim, propõem políticas para redução de natalidade, entendo que reduzir pobreza é reduzir o quantitativo de pobres (SILVA, 2010).

A tese do duplo caminho, emerge do desenvolvimentismo e se solidifica no Relatório Brundthland "Nosso Futuro Comum", da Comissão Mundial sobre Meio Ambiente e Desenvolvimento, em 1987. Nessa, a pobreza é vista como possível consequência da falta de acesso aos recursos naturais, que pode, ou não, ocasionar a destruição desses. Assim, tem-se uma abordagem dual para a estabilização ecológica via a sustentabilidade ambiental e social, alcançada através do combate à pobreza (SILVA, 2010). Essa tese, tônica desde a década de 1990, entende a "questão ambiental" como consequência do subdesenvolvimento a ser superado via "o desenvolvimento sustentável [...] aquele que atende às necessidades do presente sem comprometer a capacidade de as gerações futuras atenderem as suas" (ONU, 1991: 46).

Entendo, em contraponto a essas duas teses, que a sustentabilidade significa que há relações interdependentes de cooperação entre os seres vivos para manutenção da vida e da biodiversidade (BOOF, 2017). Logo, nego essa perspectiva hegemônica, que concebe o desenvolvimento sinônimo de defesa das condições de reprodução do sistema capitalista; assim quando há certo ganho de sustentabilidade, se faz a partir do aprisionamento à técnica, proporcionando que "[...] a sustentabilidade ambiental (ou a existência de algumas iniciativas nesta direção) se faz em detrimento da sustentabilidade social" (SILVA, 2010: 201). Então, ao expor novas matérias primas e técnicas, o desenvolvimento sustentável é útil ao capital, por reduzir a improdutividade decorrente da insuficiente recomposição da biosfera, mas, para tal, “exigem cada vez mais sacrifícios humanos em nome do progresso técnico" (SILVA, 2010: 235). Ou seja, “[...] "a sustentabilidade ambiental" vem sendo, progressivamente, subordinada aos imperativos do mercado e atrelada à competitividade empresarial: mercantilização dos recursos naturais, a gestão ambiental empresarial e a reciclagem dos resíduos sólidos" (SILVA, 2010: 186). Enquanto "[...] a "sustentabilidade social" vem sendo tratada a partir do desenvolvimento de políticas compensatórias - sobretudo através dos programas de transferência de renda" (SILVA, 2010: 187). Tem-se, dessa forma, uma conjuntura em que a crise ecológica se soma a globalização da pobreza que marcam levantes populares por melhores condições de vida. Esses dois elementos, portanto, associados a conceituação do desenvolvimento sustentável, colaboram para que a política social seja norteada pela privatização, descentralização e focalização nos pobres (BEHRING, 2011).

Como consequência direta das mediações abordadas até aqui, tem-se o processo de 
internacionalização do combate à pobreza que "[...] expressa mais um conjunto de iniciativas orquestradas internacionalmente pelas organizações econômicas multilaterais do que um grupo de mecanismos pontuais de enfrentamento da questão social concebidos separadamente em escala nacional" (MAURIEL, 2009: 64). Essa estratégia, de fundamentação teóricometodológica liberal, a partir das teorias de desenvolvimento como liberdade de Sen (2000); capital social de Coleman (2000) e capital humano de Schultz (1973), está organizada em três eixos: a) conceitos de pobreza e de pobre; b) entendimento das causas da pobreza; c) recomendações de políticas para combate à pobreza (UGÁ, 2008). A partir desses colaboradores, a pobreza é vista como consequência direta das escolhas pessoais, que impedem a aquisição de recursos e rendimentos; logo, o pobre é responsabilizado pelo seu bem-estar, que deve ser obtido via mercado, e visto como um não sujeito; e, consequentemente, as políticas sociais públicas, com orçamento reduzido, devem, principalmente, ofertar serviços nas áreas de saúde, educação, trabalho e renda, concessão de microcrédito, e, excepcionalmente, serviços para proteger da miséria, fome e morte. O que configura uma estratégia dual para o alívio da pobreza, combinando “[...] focalização nos pobres e empréstimos para promoção de bem-estar com uma ênfase na importância do crescimento e reforço dos mecanismos de mercado" (MAURIEL, 2008: 215). O processo de internacionalização do enfrentamento da pobreza tratase de uma orientação teórico-metodológica e ideo-política da gestão de recursos, próprios de uma estratégia hegemônica ${ }^{2}$ (AUTOR, 2014) que visa a manutenção do capitalismo, uma vez que ignora a pobreza enquanto uma expressão da "questão social" ${ }^{3}$. Observa-se, portanto, que “[...] o equacionamento da relação entre meio ambiente e pobreza, premido pela lógica da acumulação capitalista, far-se-á sempre limitado ou não se fará" (SILVA, 2010: 204), através de programáticas, como, recentemente, a Agenda 2030 da ONU e os ODS.

\section{O processo de construção da Agenda 2030 da ONU}

O processo de construção da estratégia hegemônica de desenvolvimento sustentável tem sua protoforma na década de 1950, quando a preocupação com o meio ambiente se amplia diante aos crimes $^{4}$ ambientais. Entretanto, somente na década de 1970, torna-se alvo de discussão e intervenção da ONU, que protagoniza marcos centrais rumo a Agenda 2030:

\footnotetext{
${ }^{2}$ Consideramos como uma estratégia, pois se insere em arena de disputa, e de forma hegemônica por deter predominância no processo de enfrentamento da pobreza, enquanto uma expressão da "questão social" (AUTOR, 2014) e da crise ecológica, particularidade da "questão ambiental" (SILVA, 2010).

${ }^{3}$ Colocamos aspas na expressão questão social para diferenciá-la da apropriação que dela foi feita pelo ideário burguês que a nega como consequência do ordenamento capitalista (NETTO, 2001).

${ }^{4}$ Assume-se a palavra crime para se contrapor as expressões de "acidente", "tragédia", "desastre", por defender que tais fatos possuem responsáveis e não apresentam caráter eventual.
} 
Conferência sobre o Meio Ambiente Humano (1972); Estratégia de Conservação Mundial (1980); Comissão Mundial sobre o Meio Ambiente e Desenvolvimento (1987); Conferência sobre Meio Ambiente e Desenvolvimento Sustentável (1992); Cúpula do Milênio (2000); Cúpula sobre Desenvolvimento Sustentável (2002); Conferência sobre Desenvolvimento Sustentável (2012); Cúpula sobre Desenvolvimento Sustentável (2015) (PNUMA, 2004).

Na década de 1970, tem-se o primeiro marco, a Conferência sobre o Meio Ambiente Humano, em Estocolmo, de 1972, que cunha a Declaração de Estocolmo, expondo que a proteção ambiental não pode ser usada como pretexto para que se desacelere o progresso econômico de países emergentes, sendo a primeira soft law sobre desenvolvimento sustentável. Além disso, recomenda a criação, ocorrida em 1972, do Programa das Nações Unidas para o Meio Ambiente (PNUMA, 2004).

Posteriormente, na década de 1980, a Estratégia de Conservação Mundial, publicada em 1980, por PNUMA, União Internacional para a Conservação da Natureza (UICN) e Fundo Mundial para a Natureza (WWF), reafirma a Declaração de Cocoyoc, de 1974, em que a degradação ambiental é vista como consequência dos impactos destrutivos do uso exacerbado de recursos pelos ricos e da luta pela sobrevivência dos pobres, indicando o enfrentamento a partir de esforços de longo prazo, que considerem a integração entre meio ambiente e desenvolvimento (PNUMA, 2004). Além disso, a Comissão Mundial sobre o Meio Ambiente e Desenvolvimento, ou Comissão Brundtland, criada em 1983, apresenta em 1987, o relatório Nosso Futuro Comum consolidando o conceito de desenvolvimento sustentável baseado na tese do duplo caminho.

Seguindo, na década de 1990, por sua vez, tem-se a Conferência das Nações Unidas para Meio Ambiente e Desenvolvimento - conhecida também como Cúpula da Terra, Rio-92 ou Eco-92. Realizada em 1992, esta é a maior conferencia desde 1970, sendo responsável por ascender o desenvolvimento sustentável a um pacto global, por via da Agenda 21 Global "Cuidando do Planeta Terra: uma estratégia para o futuro da vida" - uma programática de ações mundiais afim de que "se integrem as preocupações relativas a meio ambiente e desenvolvimento" (ONU, 1992, p.1).

A consolidação do desenvolvimento sustentável enquanto estratégia hegemônica se dá no século XXI, quando a Cúpula do Milênio, em 2000, produz o relatório Declaração do Milênio, elencando os Objetivos de Desenvolvimento do Milênio (ODM) ${ }^{5}$, para “promover um

\footnotetext{
5 ODM: 1. Erradicar a pobreza extrema e a fome; 2. Alcançar a educação primária universal; 3. Promover a igualdade de gênero e capacitar as mulheres; 4. Reduzir a mortalidade infantil; 5. Melhorar a saúde materna; 6. Combater o VIH/SIDA, a malária e outras doenças; 7. Assegurar a sustentabilidade ambiental; e 8. Desenvolver
} 
desenvolvimento verdadeiramente sustentável", no marco do "apoio aos princípios do desenvolvimento sustentável, enunciados na Agenda 21" (ONU, 2000: 10). Com o encerramento do prazo para alcance dos ODM, realiza-se a Conferência sobre Desenvolvimento Sustentável (Rio +20), em 2012, cujo relatório O Futuro que queremos, aponta lineamentos que darão forma, na Cúpula do Desenvolvimento Sustentável, em 2015, ao documento intitulado Transformando Nosso Mundo: Agenda 2030 para o desenvolvimento Sustentável. Essa última programática, em síntese, estima a construção de "um mundo em que a democracia, a boa governança e o Estado de Direito, bem como um ambiente propício em níveis nacional e internacional, são essenciais para o desenvolvimento sustentável, incluindo crescimento econômico inclusivo e sustentado, desenvolvimento social, proteção ambiental e erradicação da pobreza e da fome" (ONU, 2017: 4). Pra tanto, o documento estabelece dezessetes Objetivos de Desenvolvimento Sustentável ${ }^{6}$ (ODS) - dentre os quais o ODS 1: Acabar com a pobreza em todas as suas formas, em todos os lugares - a serem concretizados por via da Parceria Global para o Desenvolvimento Sustentável - uma programática aplicável a todos, mas respeitando as "realidades nacionais, capacidades e níveis de desenvolvimento e [...] as políticas e prioridades nacionais". Portanto, o documento estabelece que os ODS "envolvem todo o mundo, igualmente os países desenvolvidos e os em desenvolvimento" (ONU, 2017: 3), sendo os países membros da ONU, todos seus signatários, dentre eles Brasil e Cuba.

\section{Similitudes e particularidades em Brasil e Cuba}

A Agenda 2030 da ONU entra oficialmente em vigor em primeiro de janeiro de dois mil e dezesseis, passando a nortear o planejamento local e global de países em todo o globo. Assim, há a ratificação dos norteamentos teórico-metodológicos que constituem o pacto em torno do desenvolvimento sustentável, construído desde a década de 1950 e absorvidos pela agenda dos governos nacionais e da sociedade civil, porém não de forma homogênea.

No que tange ao Brasil trata-se de um país de território continental, sendo o maior da América Latina, e o quinto do mundo. É o único país latino americano cuja língua oficial não é o espanhol, e sim o português. Apresenta mais de duzentos e sete milhões de habitantes, com predominância urbana e maioria do sexo feminino e da raça/etnia negra. Em relação a sua

uma parceria global para o desenvolvimento (ONU, 2000).

${ }^{6}$ ODS: 1. Erradicação da pobreza; 2. Fome Zero; 3. Boa saúde e bem-estar; 4. Educação de qualidade; 5. Igualdade de gênero; 6. Água limpa e saneamento; 7. Energia acessível e limpa; 8. Emprego digno e crescimento econômico; 9. Indústria, inovação e infraestrutura; 10. Redução da desigualdade; 11. Cidades e comunidades sustentáveis; 12. Consumo e produção responsáveis; 13. Combate as alterações climáticas; 14. Vida de baixo d'água; 15. Vida sobre a terra; 16. Paz, justiça e instituições fortes; 17. Parcerias em prol das metas (ONU, 2017). 
formação histórico social, destaca-se que se trata de um país com muitas pessoas pobres, pois apesar de apresentar uma boa taxa de crescimento econômico, com um dos maiores montantes de Produto Interno Bruto (PIB) e taxa de renda per capita de nível médio, caracteriza-se pela ausência da divisão equitativa da riqueza coletivamente produzida que se manifesta na desigualdade e grande concentração de renda (MOREIRA; BRAGA; TOYOSHIMA, 2017). Nesse sentido, apesar da redução a um sétimo da pobreza e à metade da extrema pobreza, entre os anos de 2001 a 2015 (ONU, 2015), essencialmente, não houve alteração no que tange “[...] a prioridade da política econômica que continua voltada para os interesses de mercado em detrimento das reformas estruturais necessárias para a real superação do grave fenômeno da pobreza e essenciais para engendrar um processo de desenvolvimento sustentável" (MOREIRA; BRAGA; TOYOSHIMA, 2017: 4). Além disso, apresenta um processo recente de redemocratização, após a ditadura militar de 1964 a 1985, em que se deu a promulgação da constituição federal em 1988, indicando traços da socialdemocracia europeia e ratificando uma sociedade baseada na propriedade privada, própria do capitalismo. Sendo que, em seguida, na década de 1990, têm-se a adoção de medidas neoliberais, dando início as contra-reformas (BEHRING, 2003), e do alinhamento político e programático a estratégia hegemônica do desenvolvimento sustentável (SILVA, 2010). Essa última se expressa, por exemplo, na formulação da Agenda 21 brasileira (SILVA, 2010); na adesão ao horizonte dos ODM (BRASIL, 2014); no pareamento ao processo de internacionalização do combate à pobreza (MAURIEL, 2008) com a elaboração do Plano Brasil Sem Miséria, do Programa Fome Zero e do Programa Bolsa Família, entre outros; e por fim, a colaboração e alinhamento à Agenda $2030^{7}$.

O alinhamento do governo brasileiro a programática hegemônica do desenvolvimento sustentável ocorre desde o início de sua discussão e se desdobra nos momentos seguintes, como se pode observar, por exemplo, em quatro documentos. O primeiro, trata-se do documento Negociações da Agenda de Desenvolvimento Pós-2015: Elementos Orientadores da Posição Brasileira, cunhado em 2014, com o objetivo de "[...] orientar os negociadores brasileiros nas discussões do Grupo de Trabalho Aberto sobre Objetivos de Desenvolvimento Sustentável, constituído no âmbito da Assembleia-Geral das Nações Unidas (GTA-ODS, 2014: 9). O documento se constitui a partir da contribuição do Grupo de Trabalho Interministerial sobre a

\footnotetext{
${ }^{7}$ Colaboração expressa no documento "NEGOCIAÇÕES DA AGENDA DE DESENVOLVIMENTO PÓS-2015: ELEMENTOS ORIENTADORES DA POSIÇÃO BRASILEIRA" (http://www4.planalto.gov.br/ods) e na participação do IBGE presidindo a Comissão de Estatística das Nações Unidas, para aferir os ODS (http://www.brasil.gov.br).
} 
Agenda Pós-2015, da sociedade civil, e de entidades municipais. Neste, defende-se que “convém preservar o caráter transversal da dimensão ambiental, bem como a referência equilibrada às três dimensões que integram o conceito de desenvolvimento sustentável, tal como consagrado na Declaração do Rio e nos Acordos Multilaterais Ambientais" (GTA-ODS, 2014: 9). Por sua vez, a declaração mencionada trata-se do Relatório da Conferência das Nações Unidas sobre Desenvolvimento Sustentável (RIO + 20) em que se assume o “[...] compromisso com o desenvolvimento sustentável e com a promoção de um futuro econômico, social e ambientalmente sustentável para o nosso planeta e para as atuais e futuras gerações" (ONU, 2012: 3). Com a consolidação da Agenda 2030, o Governo Federal, por meio da Secretaria de Governo, cria a Comissão Nacional para os Objetivos de Desenvolvimento Sustentável, em outubro de 2016, via o Decreto $n^{\circ}$ 8.892, de 27 de outubro de 2016. Além disso, uma vez constituída, passou a ser regulamentada pela Portaria $n^{\circ} 81$, de 11 de outubro de 2017, que dispõe acerca do Regimento Interno da Comissão Nacional para os Objetivos de Desenvolvimento Sustentável (BRASIL, 2017a), sendo determinado que ela possui natureza consultiva e finalidade de "[...] internalizar, difundir e dar transparência ao processo de implementação da Agenda 2030 para o Desenvolvimento Sustentável da Organização das Nações Unidas". Além do âmbito governamental, têm-se as organizações da sociedade civil, como por exemplo, a Estratégia ODS e o Grupo de Trabalho da Sociedade Civil para Agenda $2030^{8}$.

Diante a isso, o Brasil situa-se alinhado à estratégia hegemônica de desenvolvimento sustentável cunhada pela ONU na Agenda 2030, visto que corrobora com seu conceito de desenvolvimento sustentável e elenca a promoção de políticas públicas, a mudança no padrão de consumo e a inovação tecnológica como meio de melhoria socioeconômica e ambiental, sem mencionar a necessidade de transformação das relações sociais capitalistas.

Em relação a Cuba, trata-se de um país de território insular, o maior em população no Caribe, com mais de onze milhões de habitantes, de predominância urbana e maioria do sexo masculino. Elementos importantes de diferenciação à formação social brasileira se dão, principalmente, após 1959, com o triunfo da revolução. Nesse momento, o país declara-se socialista, tendo o apoio da URSS, e aplica “[...] seu programa de medidas sociais iniciais de amplo alcance popular como as de reforma agrária, alfabetização, eliminação de despejos em moradias, entre outras" (GARCÍA, 2013: 165, tradução nossa). Este visou enfrentar mazelas, citadas por Fidel em seu discurso de defesa pelo assalto ao quartel Moncada (CASTRO, 2011).

\footnotetext{
${ }^{8}$ Ambas se constituem como organização representativa composta por sociedade civil, setor privado, governos locais e academia, visando debater e propor ações para concretizar os ODS no Brasil.
} 
Isto é "a Constituição da República de Cuba define o Estado cubano como um estado socialista dos trabalhadores para o gozo do bem-estar individual e coletivo, baseado na justiça social e na solidariedade humana" (GARCÍA, 2013: 165). Entretanto, com o colapso do bloco soviético, há um recrudescimento do bloqueio econômico, orquestrado pelos Estados Unidos desde 1967, levando a ajustes, mas sem abandono do caráter socialista e da planificação centralizada (GARCÍA, 2013). Isso possibilitou a garantia de atuais baixos índices de pobreza, como expõe o relatório Los Objetivos de Desarrollo del Milenio Cuba Edición 2015, da Oficina Nacional de Estadística e Infomación (CUBA, 2017). Nesse, constata-se que em 2014 o país apresentava destacáveis índices sociais, como: taxa de emprego de 97,3\%; taxa de alfabetização de 100\%; taxa de incidência de HIV na população de 15 a 24 anos de 0,09\%; ausência desnutrição infantil (CUBA, 2017).

Observado esses pontos, pode-se considerar que o modelo cubano de sustentabilidade social e ambiental se inicia na década de 1970, mas passa a ter maior investimento a partir da Conferência das Nações Unidas para Meio Ambiente e Desenvolvimento, em 1992, quando Fidel alerta que "uma importante espécie biológica corre o risco de desaparecer devido à rápida e progressiva liquidação de suas condições naturais de vida: o homem" (CASTRO, 2017, tradução nossa). Esse clamor foi assimilado pelo povo cubano, que passa a construir uma programática contra hegemônica de desenvolvimento sustentável, que se expressa inicialmente em três documentos: i) Ley $n .81$ del Medio Ambiente, de 1997; ii) Estrategia Ambiental Nacional 1997-2010; e iii) Estratégia Nacional de Educacion Ambiental (EDITORIAL MONTEVERDIA, 2017, tradução nossa).

A Ley n. 81, em vigor, define como objeto "estabelecer os princípios que regem a política ambiental e as normas básicas que regulam a gestão ambiental do Estado e as ações dos cidadãos e da sociedade em geral, a fim de proteger o meio ambiente e contribuir para a consecução dos objetivos de desenvolvimento sustentável do país". Essa define o desenvolvimento sustentável como "processo de elevação sustentada e equitativa da qualidade de vida das pessoas, através do qual se busca o crescimento econômico e a melhoria social, em uma combinação harmoniosa com a proteção ambiental, para que as necessidades das gerações atuais sejam atendidas, sem comprometer a satisfação das necessidades das gerações futuras" (CUBA, 1997, tradução nossa).

Acerca do segundo e terceiro marco, são inicialmente concebidos de forma separada, sendo depois integrados, sendo que, atualmente, a educação ambiental trata-se de um dos projetos que compõe a Estratégia Ambiental Nacional 2016-2020 (CUBA, 2016), que é a “expressão da política ambiental cubana, na qual se refletem suas projeções e principais 
diretrizes" (CUBA, 1997).

Concernente com esse desenvolvimento histórico, no $7^{\circ}$ Congresso do Partido Comunista (PCC) foi aprovado dois documentos centrais para o entendimento da estratégia cubana de desenvolvimento sustentável. O primeiro compreende o Proyecto de Conceptualización del Modelo Económico y Social Cubano de Desarrollo Socialista, em que "a conceituação aborda, como nunca antes para Cuba, a categoria da sustentabilidade como elemento substancial da base do desenvolvimento do país" (DUQUE, 2016, p.1, traduação nossa). Esse documento corrobora a construção de uma sociedade próspera e sustentável, conforme definida pelo VI Congresso do PCC, em 2011, no documento Lineamientos de la Política Económica y Social del Partido y la Revolución56. Desse modo, define que o objetivo estratégico do modelo cubano

é impulsionar e consolidar a construção de uma sociedade socialista próspera e sustentável em termos econômicos, sociais e ambientais, comprometida com o fortalecimento dos valores éticos, culturais e políticos forjados pela Revolução, de forma soberana, independente, socialista, democrática, próspera e sustentável (CUBA, 2017: 6).

O segundo documento, o Proyecto Plan Nacional de Desarrollo y Económico y Social hasta 2030: Propuesta de Visión de la Nación, Ejes y Sectores Estratégicos define seis eixos estratégicos de ação: governo eficaz e socialista; integração social, transformação produtiva e inserção internacional; infraestrutura; potencial humano; ciência, tecnologia e inovação; recursos naturais e meio ambiente; e desenvolvimento humano, justiça e equidade. Isto é, trata de apresentar a sistematização do Sistema Nacional de Planificação, incluindo as estratégias, objetivos e ações econômicas, políticas e sociais, ou seja, “[...] constituirá a principal ferramenta para alcançar os objetivos essenciais que se afirmam na Conceituação do Modelo Econômico e Social de Cuba de Desenvolvimento Socialista" (CUBA, 2017: 16).

\section{Considerações Finais}

A estratégia hegemônica de desenvolvimento sustentável constitui um pacto global hegemônico em que os países da periferia do capitalismo, como Brasil e Cuba, são vistos como centrais para alcançar a sustentabilidade social e ambiental por via do combate à pobreza e incremento tecnológico, muitas vezes, atribuindo a esses a responsabilidade de seu empobrecimento e degradação ambiental.

Ao analisar países periféricos que são signatários da Agenda 2030, observamos que esse alinhamento não se dá de forma passiva - como no caso do Brasil, que contribui ativamente para a elaboração da Agenda 2030 - nem tão pouco de forma subserviente - como no caso de 
Cuba, que constrói o desenvolvimento sustentável a partir de um alinhamento ídeo-político divergente da Agenda 2030. Além disso, é possível inferir que embora ambos os países sejam signatários, Brasil e Cuba assumem distintos projetos societários, capitalista e socialista respectivamente, que culmina em uma gestão socioambiental divergente na América Latina. Assim, em Cuba a melhoria nos índices socioambientais é produto de um projeto socialista que prioriza o desenvolvimento humano, buscando um equilíbrio entre sociedade e meio ambiente, enquanto no Brasil tem-se uma estratégia centrada em políticas sociais compensatórias de combate à pobreza.

Assim, é possível aferir que a redução dos índices de pobreza e da degradação ambiental - como, por exemplo, apresentado no Relatório Final dos Objetivos de Desenvolvimento do Milênio (ONU, 2015) - são melhorias pontuais e majoritariamente decorrentes de incremento técnico e políticas sociais compensatórias. Pois, o deterioramento da condição de vida humana e do meio ambiente trata-se de um processo profundo e em curso, que requer uma mudança planetária anti-capitalista capaz de fundar uma forma nova de organizar a sociedade global.

\section{Referências}

A estratégia BEHRING, Elaine Rosseti. Brasil em contra-reforma. São Paulo: Cortez, 2003. Política Social no capitalismo tardio. 5. ed. São Paulo: Cortez, 2011.

BRASIL. Objetivos de Desenvolvimento do Milênio. Brasília: IPEA, 2014.

BOFF, Leonardo. Os impasses da expressão “Desenvolvimento sustentável”. In: Brasil. Agenda 21 e sustentabilidade. Disponível em: http://www.mma.gov.br. Acesso em:20 set. 2017.

CASTRO, Fidel. A história me absolverá. 3 ed. São Paulo: Expressão Popular, 2011.

CHESNAIS, François; SERFATI, Claude. "Ecologia" e condições físicas da reprodução social: alguns fios condutores marxistas. Crítica Marxista, São Paulo, Xamã, n.16, 2003.

COLEMAN, James. Social Capital in the Creation of Human Capital. In: DASGUPTA, P.;

SERAGELDIN, I. (Org.). Social Capital: a Multifaceted Perspective. Washington, D.C., The World Bank, 2000.

CUBA. ASAMBLEA NACIONAL DEL PODER POPULAR. LEY N. 81 DE 11 DE JULIO DE 1997.

CUBA. Estratégia Ambiental Nacional 2016-2020. Havana: ONE, 2016.

CUBA. Los Objetivos de Desarrollo del Milenio Cuba Edición 2015. Havana: ONE, 2015.

CUBA. VI CONGRESSO DO PARTIDO COMUNISTA DE CUBA. LINEAMENTOS DA POLÍTICA ECONÓMICA E SOCIAL DO PARTIDO E A REVOLUÇÃO. 2011.

CUBA. VII CONGRESSO DO PARTIDO COMUNISTA DE CUBA TABLOIDE ESPECIAL. PCC, 2016.

EDITORIAL MONTEVERDIA. La Estrategia Ambiental Nacional 2016-2020: en la búsqueda de un socialismo próspero y sostenible. Monteverdia, v. 10, n. 1, 2017.

GARCÍA, Rita Castiñeiras. CUBA: LA CUESTIÓN SOCIAL Y LAS POLÍTICAS SOCIALES EN CUBA. In: GARCIA; M. L. T.; RAIZER, E. C. A questão social e as políticas sociais no contexto latino-americano. Vitória: EDUFES, 2013.

GIL, Antônio Carlos. Métodos e técnicas de pesquisa social. 6. ed. São Paulo: Atlas, 2002.

GOLDSTEIN, Fred. Low-wage capitalism: colossus with feet of clay. New York: World View 
Forum, 2008.

MARX, Karl. O capital: crítica da economia política. Livro I, vol. II. Rio de Janeiro: Bertrand, 1989.

O capital: crítica da economia política. Livro I, vol. I. São Paulo: nova cultural, 1996. Teses sobre Feuerbach. São Paulo: Sociais, 1977.

MASCARENHAS, R. CRÍTICA A CONCEPÇÃO HEGEMÔNICA DE "ERRADICAÇÃO DA POBREZA". 2014. Dissertação (Mestrado em Política Social) - Universidade Federal do Espírito Santo, Vitória, 2014.

MAURIEL, Ana Paula. Combate à pobreza e desenvolvimento humano. Tese (Doutorado em Ciências Sociais) - Universidade Estadual de Campinas, Campinas, 2008.

. Relações internacionais, política social e combate à pobreza. Em pauta, Rio de Janeiro, v.6, n.23, 2009.

MOREIRA, Renata Couto; BRAGA, Marcelo José; TOYOSHIMA, Silvia Harumi. CRESCIMENTO E DESIGUALDADE. Anais do $38^{\circ}$ Encontro Nacional de Economia, 2010. Disponível em: http://www.anpec.org.br/encontro2010/inscricao /arquivos/000cc7b8226e1f2d18e0d2072469dddcfee.pdf. Acesso em: 10 jul. 2017.

MOTA, Ana Elizabete; SILVA, Maria das Graças e. A questão ambiental e o contraditório discurso da sustentabilidade. Praia Vermelha, Rio de Janeiro, v.19, n.2, 2009.

NETTO, José Paulo. Cinco notas a propósito da "questão social". Temporalis, Porto Alegre, n.3, 2001.

ONU. Organização das Nações Unidas. Agenda 21. Nova York: UNIC, 1992.

. Comissão Mundial sobre meio Ambiente e Desenvolvimento. Rio de Janeiro: FGV, 1991.

. Declaração do Milênio. Nova York: UNIC, 2000.

Relatório dos Objetivos de Desenvolvimento do Milênio 2015. Nova York: UNIC, 2015 .

Transformando Nosso Mundo: A Agenda 2030 para o Desenvolvimento Sustentável. Disponível em: https://nacoesunidas.org. Acesso em: 10 jul. 2017.

PNUMA. Programa das Nações Unidas para Meio Ambiente. Perspectivas do Meio Ambiente Mundial 2002 GEO-3. Brasília: IBAMA/PNUMA, 2004.

SCHULTZ, Theodore William. O capital humano. Rio de Janeiro: Zahar, 1973.

SEN, Amartya. Desenvolvimento como liberdade. São Paulo: Companhia das Letras, 2000.

SILVA, Maria das Graças e. Questão ambiental e desenvolvimento sustentável. São Paulo: Cortez, 2010.

UGÁ, Vivian Dominguez. A questão social como "pobreza". Tese (Doutorado em Ciências Humanas), Instituto Universitário de Pesquisas do Rio de Janeiro, Rio de Janeiro, 2008.

ZEMELMAN, Hugo. Alguns reflexiones metodológicas a partir del problema de las investigaciones comparativas. In: Krawczyk, N. R.; Wanderley, L. E. América Latina. São Paulo: Cortez, 2003. 